\title{
The Application for Controlling Theory and Methods in Intelligent Test System
}

\author{
Ruicheng Li \\ Shandong Youth University of Political Science, Jinan 250103, China \\ Tel: 86-531-58997405 E-mail: LRC@sdyu.edu.cn
}

\begin{abstract}
The Computer Aided Instruction is the very important application field of computer technique. Computer auxiliary examination management system is the important link of the Computer Aided Instruction, and it is an effective means for teaching evaluation. This paper introduces the application of intelligent examination system's control theory and method. It realizes the artificial and automatic control to the hard or easy test questions and the distribution of chapters. It adapts to multi-levels, multi-subjects. And this system is the important content of the intelligent Computer Aided Instruction.
\end{abstract}

Keywords: Computer Aided Instruction (CAI), Control theory and method, Intelligence

\section{Development Status of Intelligent Test System}

Computer auxiliary examination management system is the important link of the Computer Aided Instruction, and it is an effective means for teaching evaluation. Computer auxiliary examination management system gets a great development in these years, such as national computer rank examination, computer applied ability examination for the technical personnel throughout the country, as well as other forms of computer-aided test. The features of these examinations: firstly, examination subjects' priority to computer major; secondly, answer manners' priority to objective items; thirdly, examination manners' priority to stand-alone test; fourthly, examination settings' priority to closure property. For the past few years, other than computer subject, objective item manner, or networks manner examination system get faster research and apply. The control for item difficulty is the vitally important content of designs in intelligence examination systems.

\section{The Development Requirement for Intelligent Examination}

Compared to the shorts of the traditional ways of examination mentioned above and current situation of computer-aided test, the intelligent test system has the following features:

Firstly, the system has strong commonality. It can apply to various kinds of classes and subjects test.

Secondly, realizes separation of teaching and testing. It is in favor of objective and fair evaluation to teaching quality.

Thirdly, saves up vast of manpower and material resources. Using this system will save cost and improve efficiency in set of questions, test paper printing and binding, monitor examination and test paper read over.

Fourthly, it can improve test quality, increase the scientism and objectivity of the examination. Objectively, it can effectively prevent cheating on exams. Every examinee's papers are randomly generated by the system, these test paper are various, so they can't plagiarize each other.

Fifthly, the test time is automatically controlled. It is objective and fair, easy to control.

Sixthly, test read over and result statistics are automatic. It can shorten the test period greatly.

\section{The Application of Automatic Control Theory and Method}

The development of the theory of control is already very perfect. From classical to modern, from convention to intellection, we all can select and use it as requirement. Purpose of control is to determine the number according to the difficulty from database. The concrete achieve means will be expert table, be fuzzy logic control, and be established the mathematical model, etc.

The problem or test paper arrangement is a multi-objective constraint optimization problem. As the examination management system, it is different from the technical control or procedural control system, more appropriate to choose the control scheme of fuzzy or expert table. 
Figure 2 provides two kinds of fuzzy logic control membership functions and graphics. One is triangle, and the other is gauss form. On the basis of requirement and test again and again, make sure which kind of control mode is more appropriate for test control. The aim of control test requirements often doesn't produce precise positioning test in the problem, but we hope the system cannot be "location" in the question. This is also the difference between the manual control and the intelligent control.

\section{Realize the Control}

The index system of the test database, basically should consider of three main factors including item type, knowledge points and facility value. For example, with computer subject, item types can have a choice test, judgment, fill, answer, and operating etc. The proportion (question quantity) of each chapters and sections can be controlled, and the difficulty of the test questions also can be controlled, and we generally divide them into easy, easier, mid, harder, hard, and several levels etc.

The below project uses a form. It forms usage of the experience of relevant factors, the system, according to different difficulty and chapter and section, will select different sum from tables. For instance, according to different difficulty, some part of different test is divided into the following 5 levels, such as easy, easier, mid, harder, hard, etc. corresponding questions quantity as $\mathrm{x} 1, \mathrm{x} 2, \mathrm{x} 3, \mathrm{x} 4, \mathrm{x} 5$. We plan to select number ' $\mathrm{t}$ ' from these questions.

Suppose we will select questions number y1, y2, y3, y4, and y5 from database $\mathrm{x} 1, \mathrm{x} 2, \mathrm{x} 3, \mathrm{x} 4$, and $\mathrm{x} 5$. Obviously, $\mathrm{y} 1+\mathrm{y} 2+\mathrm{y} 3+\mathrm{y} 4+\mathrm{y} 5=\mathrm{t}$. (' $\mathrm{t}$ ' is total test question number)

We, according to expert factor and so on, ensure the below control scheme.

\begin{tabular}{|c|c|c|c|c|c|}
\hline Ratio (\%) & $\mathbf{X}_{\mathbf{1}}$ & $\mathbf{X}_{\mathbf{2}}$ & $\mathbf{X}_{\mathbf{3}}$ & $\mathbf{X}_{\mathbf{4}}$ & $\mathbf{X}_{\mathbf{5}}$ \\
\hline easy & 70 & 15 & 10 & 5 & 0 \\
\hline easier & 10 & 70 & 10 & 5 & 5 \\
\hline mid & 5 & 10 & 70 & 10 & 5 \\
\hline harder & 5 & 5 & 10 & 70 & 10 \\
\hline hard & 0 & 5 & 10 & 15 & 70 \\
\hline
\end{tabular}

According to the above plan, there are:

When we select 'easy' question, $\quad \mathrm{y}_{1}=\mathrm{t} * 70 \%$;

$\mathrm{y}_{2}=\mathrm{t} * 15 \%$;

$\mathrm{y}_{3}=\mathrm{t} * 10 \%$

$\mathrm{y}_{4}=\mathrm{t} * 5 \%$;

$\mathrm{y}_{5}=\mathrm{t} * 0 \%$

When we select 'easier' question, $\mathrm{y}_{1}=\mathrm{t} * 10 \%$;

$\mathrm{y}_{2}=\mathrm{t} * 70 \%$;

$\mathrm{y}_{3}=\mathrm{t} * 10 \%$;

$\mathrm{y}_{4}=\mathrm{t} * 5 \%$

$\mathrm{y}_{5}=\mathrm{t} * 5 \%$

When we select 'mid' question, $\quad \mathrm{y}_{1}=\mathrm{t} * 5 \%$;

$\mathrm{y}_{2}=\mathrm{t} \mathrm{t} * 10 \%$;

$\mathrm{y}_{3}=\mathrm{t} * 70 \%$;

$\mathrm{y}_{4}=\mathrm{t} * 10 \%$;

$\mathrm{y}_{5}=\mathrm{t} * 5 \%$

When we select 'harder' question, $\mathrm{y}_{1}=\mathrm{t} * 5 \%$;

$\mathrm{y}_{2}=\mathrm{t} * 5 \%$

$\mathrm{y}_{3}=\mathrm{t} * 10 \%$;

$\mathrm{y}_{4}=\mathrm{t} * 70 \%$;

$\mathrm{y}_{5}=\mathrm{t} \times 10 \%$;

When we select 'hard' question, $\quad \mathrm{y}_{1}=\mathrm{t} \times 0 \%$;

$\mathrm{y}_{2}=\mathrm{t} * 5 \%$;

$\mathrm{y}_{3}=\mathrm{t} * 10 \%$;

$\mathrm{y}_{4}=\mathrm{t}^{*} 15 \%$;

$\mathrm{y}_{5}=\mathrm{t} \mathrm{t} * 70 \%$; 
The quantity of papers must be an integer. Therefore, we need do 'fetch integer judge' for yi fig 3.

We need to randomly select assigned quantity (test quantity) serial number (test sequence number) from the set number (total question quantity), the number, of course, is not reduplicated. The smaller procedures below section by Power Script can use a programming language group that did not repeat randomly. This program, only a few words, is short but forceful. Passing through the computer test, operation is very accurate and reliable.

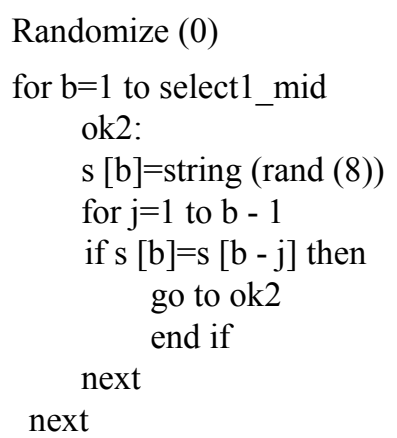

In the choosing window of automatic volumes, according to the needs, selected the difficulty level, the control system can generate the corresponding question.

\section{Conclusion}

The found of the Test-Exam Database can make the work standard convenient for evaluating teaching quality by uniform standard, and reduce the teachers' workload, and solve the traditional artificial proposition, the low efficiency, time-consuming, lack of scientific questions on narrow face, etc. In the side of test generation, by using artificial and automatic generating strategies, meanwhile fully considering the chapters of and the reasonable distribution of difficulty, volumes conditions can willfully mix. Based on the database, users can set exam papers by using artificial or automatic mode according to needs--we can complete the inquiries and output of tests and answers etc., and we also can directly precede exam on computer.

\section{References}

Chen Guangzhong etc. (1997). The General Software System Structure of High School Examination Database. The higher engineering education research. The forth of 1997.

Chen Guiyou etc. (2002). Power Builder Database Development Technology. Beijing: Mechanical industry press, 2002

Li Ruicheng \& Zhang Chenghui. (2005). A Design of Computer Aided Test Management System. Jinan University journal (natural science version). September of 2004.

Zhang Fang, Yang Tao \& Jiang, Lanling etc. (2006). Based on the genetic algorithm is intelligent computer exam system research. Agricultural Network Information. October of 2006. 


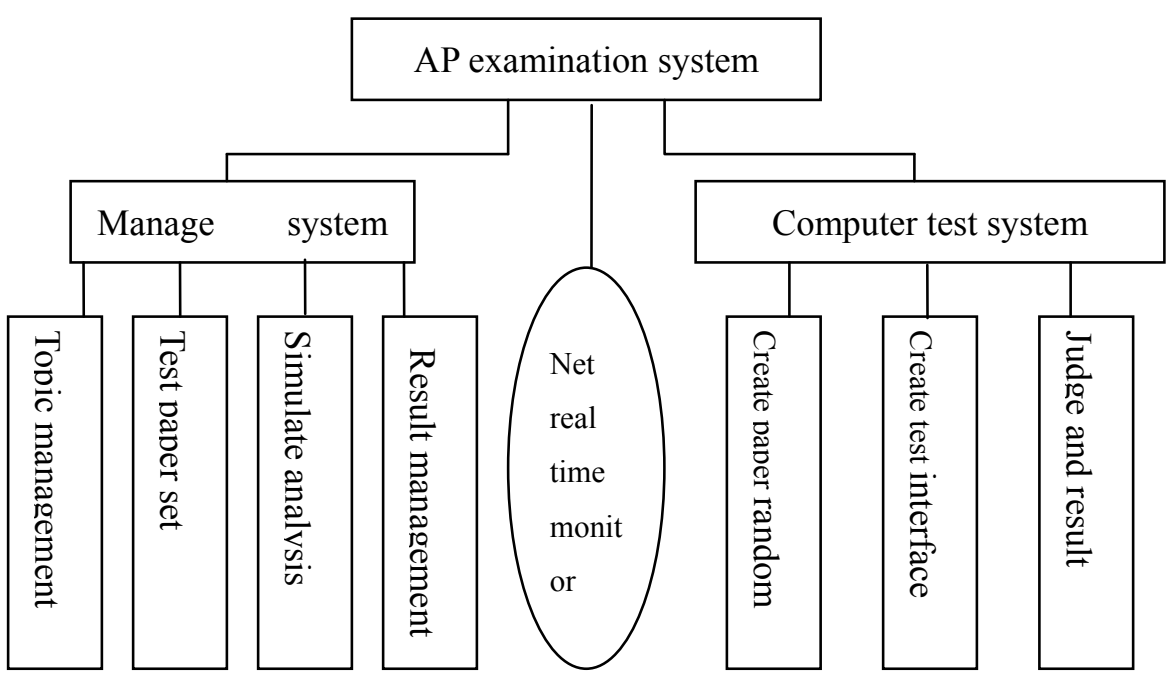

Figure 1. AP examination system
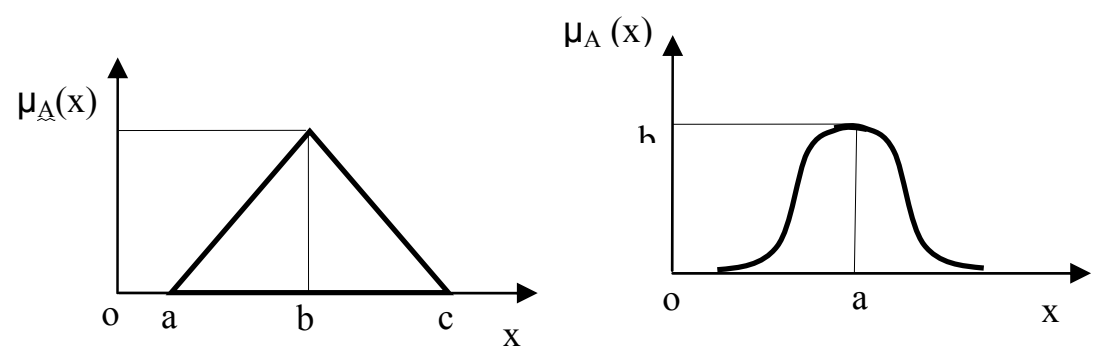

$$
\mu_{\mathrm{A}}(\mathrm{x})=\left\{\begin{array}{ll}
0 & (x \leq a) \\
\frac{x-a}{b-a} & (a<x \leq b) \\
\frac{c-x}{c-b} & (b<x \leq c) \\
0 & (x>c)
\end{array} \mu \mathrm{A}(\mathrm{x})=\mathrm{e}^{-\frac{1}{2}\left(\frac{x-a}{b}\right)^{2}}\right.
$$

Figure 2. triangle, gauss membership function and graph

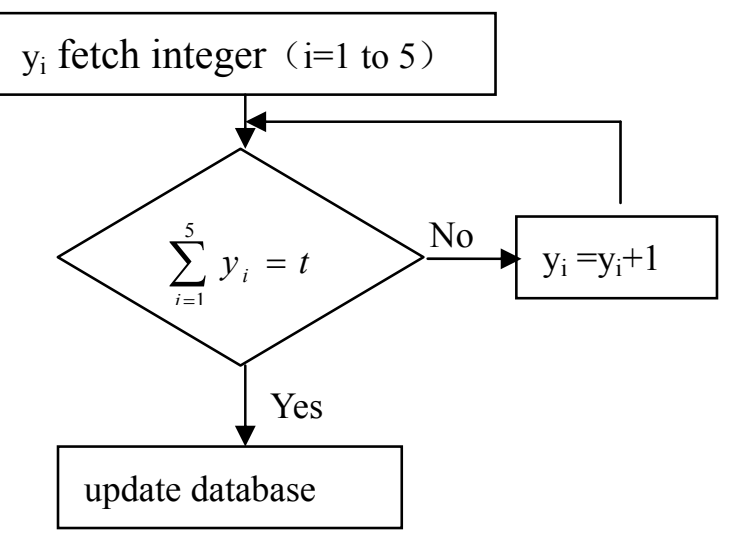

Figure $3 . \mathrm{y}_{\mathrm{i}}$ fetch integer judge 